it will continue for at least two more financial years and the text above will remain relevant for that time.

\section{References}

MetTers, J. S. 'Exemption of People with Severe Mental Impairment from Liability to pay the Community Charge' PL/CO (89), 12 November 1989.
ReED, J. 'Dear Doctor' Letter PL/CO (90) 7, 2 July 1990.

This statement includes comments and corrections made by the Department of Health and the Department of the Environment.

Dr A. R. M. Freeman

April 1991

Public Policy Committee

\title{
MRCPsych Examinations notice
}

The Court of Electors recently issued guidelines on the way in which two topics should be examined in the MRCPsych Examinations. The statements, which are summarised below, will be welcomed as a way of clarifying the many complex issues surrounding these topics, and it is hoped that they will prove to be helpful both to Examiners and candidates alike.

\section{Classification of disorders (MRCPsych Part I, Part II and Membership Examinations)}

The Clinical and Oral Examinations

All candidates will be expected to demonstrate, where necessary, a working knowledge of the ICD. It is, however, important that candidates offering the DSM classification should not be penalised, providing their presentation does justice to the clinical problem under consideration.

\section{The Written Papers}

The same considerations will apply with regard to Essay questions. In the case of the Multiple Choice and Short Answer Question Papers, any questions on classification of disorders will be confined to the principles which underlie either the ICD or DSM.

\section{Law in the Membership and MRCPsych Part II Examinations}

The Clinical and Oral Examinations

It is important that candidates should be conversant with the principles of mental health law that apply in the British Isles and other common law countries. It is also important that they are familiar with the law of one country in the United Kingdom or the Republic of Ireland. Candidates should be asked to nominate the law with which they are familiar. Those training outside the UK and Republic of Ireland (i.e. Hong Kong, Canada, USA, Australia and New Zealand) should be expected to demonstrate knowledge of British or Irish law (whichever option they may choose) at an appropriate level.

This is a complex and difficult field which poses problems for both Examiners and candidates. Much will depend upon the good sense and judgement of Examiners with regard to what should be expected of candidates. Paramount in all this is recognition that questioning on specifics of law should be tailored very carefully to each candidate's selected option.

In addition, candidates and Examiners should not depend upon numerical reference to sections of the particular law which they are describing, but should place emphasis upon a brief description of their content, e.g. 'emergency admission', 'transfer from prison', 'compulsory admission', etc.

\section{The Written Papers}

The above principles will also apply with regard to questions on Law which may appear in the Short Answer Question and/or Essay Paper.

Professor H. G. MoRGaN Chief Examiner

\section{SPECIAL ANNIVERSARY MEETING SATURDAY 27 JULY 1991}

On 27 July 1841 the Association of Medical Officers of Hospitals for the Insane was founded at Horton Road Hospital in Gloucester; 130 years later this organisation matured into the Royal College of Psychiatrists.

On 27 July 1991 a special one day meeting is being hosted jointly by the South Western Division and the History of Psychiatry Special Interest Group at Wotton House in Horton Road to celebrate 150 years of British psychiatry.

Attendance is open to all College members who book beforehand. Places will be limited to 120 . The programme and further details are available from Dr Richard Williams, Honorary Secretary of the South Western Division at the College, 17 Belgrave Square, London SWIX 8PG. 